\title{
Article \\ Subduction Zone Characterization of the Northern Papua through the Study of Earthquake History
}

\author{
Miftachul Janah ${ }^{1, *}$, Supriyadi ${ }^{1}$, Ian Yulianti ${ }^{1}$, Yuni Trisnowati ${ }^{2}$ and Andya S. P. Putro ${ }^{1}$ \\ 1 Physics Departement, Faculty of Mathematics and Natural Sciences, Universitas Negeri Semarang, \\ Jawa Tengah 50229, Indonesia; Supriyadi@mail.unnes.ac.id (S.); ianyulianti@mail.unnes.ac.id (I.Y.); \\ Andyasatyaputra@gmail.com (A.S.P.P.) \\ 2 Indonesian Agency for Meteorology, Climatology and Geophysics, Jakarta 10720, Indonesia; \\ YuniTrisnowati@gmail.com \\ * Correspondence: miftach.scientist@gmail.com; Tel.: +628-951-330-1407
}

\begin{abstract}
Papua is one of part in Indonesia which is the geology research of that place isn't developed and limited. It causes the seismotectonic of Papua hasn't been known. WinITDB was used to determine the dip angle plate which was on the north part of Papua. The determination of angle was done through seismicity's cross section analysis in the area. To show that seismicity, earthquake history data that ever occurred in the area is needed. The result on the seismicity's cross section of plane $\mathrm{A}-\mathrm{A}^{\prime}$, was confluence by two plates with angle $150^{\circ}$ against horizontal on the depth up to $\pm 68 \mathrm{~km}$. On the seismicity's cross section of plane B-B' had angle $135^{\circ}$ against horizontal on the $\pm 82 \mathrm{~km}$ depth. On the plane $\mathrm{C}-\mathrm{C}^{\prime}$ seismicity's cross section, was confluence of two plate which located between $-1,77^{\circ} \mathrm{S}$ until $-4,97^{\circ} \mathrm{S}$ subducted until $171 \mathrm{~km}$ depth on $1,38^{\circ} \mathrm{N}-4,97^{\circ} \mathrm{S}$. It proved that subduction characteristic in the northern Papua which was Australia continent plate subducted to north, followed by collision and the Pacific plate subduction on New Guinea. It is also confirmed by focus mechanism analysis which showed the earthquake activities are controlled by the not really deep active fault.
\end{abstract}

Keywords: Northern Papua; Subduction; Seismicity

\section{Introduction}

Eastern Indonesia is located inside the region of complex tectonics controlled by the motions of the Eurasia, Australia, Pacific, Philippine Sea, and numerous small plates (Figure 1). This area is also known for its high seismic activity with frequent events of magnitude 7 to 8 . Within the Irian Jaya (Papua) region, teh Australia plate collides with the oceanic Pacific and Philippine Sea plates at a rate of $110 \mathrm{~mm} / \mathrm{yr}$ and an azimuth of 245 degree [1]. GPS measurements of crustal deformation [2,3] and seismic profiling studies [4] show that the convergence between the Australia and Pacific plates in the Irian Jaya region is partially accomodated by crustal thickening in the onland regions of the Bird's Head plate. The rest of the convergence between two paltes is accomodated by the southward subduction of the oceanic plate beneath the Bird's Head plate along the New Guinea and Manokwari trenches $[2,5]$.

The convergence between the Pacific plate relative to Australia is partly accomodated by thrusting in the Mamberamo Range. Earthquakes have three slip vectors roughly parallel to the plate convergence [6]. In the fold and thrust belt of Irian Jaya, slip is accommodated by both strike slip and thrusts [7]. Most of the thrusts are located in the south of the belt between the frontal thrust and the axis of the range. 


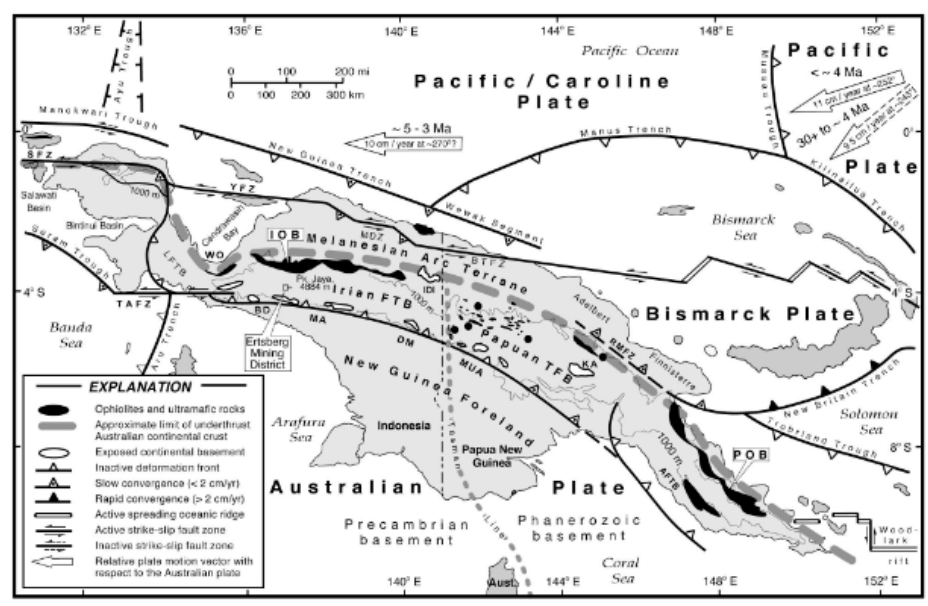

Figure 1. Schematic map of the Eastern Indonesian region showing the global trend of block motion at boundaries independently of the velocities (solid arrows) and plate motion relative to fixed Eurasia [8].

The fold and thrust belt of Irian Jaya and Papua New Guinea by $\mathrm{N} 100^{\circ} \mathrm{E}$ over $1000 \mathrm{~km}$, between $136^{\circ} \mathrm{E}$ and $142^{\circ} \mathrm{E}$, and bends abruptly at both ends. All along the belt, deformation is accommodated by $\mathrm{N} 100^{\circ} \mathrm{E}$ trending and strike-slip faults [9]. But recent motion is difficult to interpret and to date because it runs parallel to the fabric of the metamorphic rocks. Structures are deflected to a $\mathrm{N} 130^{\circ} \mathrm{E}$ direction in various places of the belt, indicating they have been dragged toward the Southwest. A good example of such structure is the thrust present in the Baliem River along the Wamena Valley. Hence everywhere along the belt the structures are compatible with Northeast-Southwest $\left(\mathrm{N} 40^{\circ} \mathrm{E}\right)$ oriented compression, and the deformation was distributed either by folds and thrusts perpendicular to the compression. The directions of motion may have varied in space and time during the Pliocene and the Quaternary. This study investigates the escape zone into two areas. Where different tectonic deformation occurs. The first area is a large strip in the southern part of the Irian Jaya, which includes the front of the belt and its westward extension along the Tarera fault. The second area is a $N 70^{\circ} \mathrm{E}$ strip between the eastern end of the central fold and thrust belt.

On July 27, 2015 UT, an earthquake doublet with moment magnitudes of 6.9 and 5.0 occured in Mamberamo Raya, northern Papua (BMKG Earthquake Database, 2015). According to the Global CMT Project, the earthquake doublet of July 27 had similar seismic moments and thrust faulting mechanism that corresponds to the faulting on the plate boundary along the New Guinea trench. These focal mechanism are consistent with the subduction direction of the oceanic slab beneath the Bird's Head plate. These earthquake doublets are represented by the similarly sized events that occur at nearly the same time and location [10-13]. Lay and Kanamori [14] reported that such a doublet behavior is a true characteristic of the regions due to the complex tectonic settings. They explained the doublet events as a result of the mechanism of seismic triggering that reflects the state of stress on the fault plane and lithospheric coupling between the Pacific and Australia plates. Detailed knowledge of the source process and slip distribution of this earthquake doublet is essential for understanding the state of stress in the Papua region. It is also helpful for understanding the triggering mechanism of earthquake in a subduction zone. In this research, we would analyze subduction zone by performed cross section of seismicity using software WinITDB (Windows Integrated Database).

Based on previous research Study of Earthquake History methods were applied to Subduction Zone Characterization in many different parts of the world, see for examples: Boore [15] Simulation of ground motion using the stochastic method. Brown et al [16] Deep low-frequency earthquakes in tremor localize to the plate interface in multiple subduction zones. KanHayes et al [17] A threedimensional model of global subduction zone geometries. Kanamori [18] Rupture process of subduction-zone earthquakes. 
The research which covered collecting, tabulating, and data interpreting was done in Earthquake Center Regional Office 7 Indonesian Agency for Meteorology, Climatology and Geophysics (BMKG) of Yogyakarta by taking the research location in Papua with the coordinate of $0^{\circ} \mathrm{N}-5^{\circ} \mathrm{S}$ dan $135^{\circ} \mathrm{E}-$ $141^{\circ} \mathrm{E}$. The data which was used in this research was the earthquake data in the coordinate $\left(0^{\circ} \mathrm{LU}\right)$ -

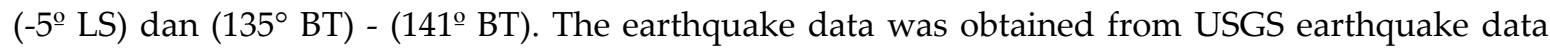
recording. Those data contained the earthquake information (earthquake parameter) from an earthquake event. In this research, the earthquake parameter which was used included, the arrival time of the earthquake, the position of the latitude-longitude, the depth, and the magnitude.The data tabulation of the northern part of Papua's earthquake used some software like Software WinITDB (Windows Integrated Tsunami Database), Software Surfer12, Software Arc View Gis.

The earthquake data which was obtained from USGS earthquake data recording was converted to software data format WinITDB manually using notepad program. This was due to the data format from USGS different from the data format in the WinITDB software. After going through the conversion process, the data was then processed using WinITDB software. It produced the spread of epicenter or seismicity map where the spread of hypocenter was analyzed using cross section on the latitude and the depth so that it was obtained plate penunjaman graphic. Besides, plate penunjaman graphic was also visualized through three-dimensional view by processing and data interpreting using Surfer 12 software. To support the subduction zone characteristic, the analysis of earthquake activity was done through seismotectonic study in the area of research by processing the supporting data in the form of focus mechanism from earthquake event with magnitude $\geq 6$ Richter Scale which occurred in Papua subduction zone using Arc ViewGis software.

\section{Results}

\subsection{Seismicity Cross Section Plane A-A'}

Seismicity cross section plane A-A', which could be seen on Figure 3.1 showed the spread of hypocenter in the region of Pacific ocean with cross section on the point of $7.10^{\circ} \mathrm{N}$ and $134.88^{\circ} \mathrm{E}-$ $138.60^{\circ} \mathrm{E}$ with a distance of $731 \mathrm{~km}$ sea and the depth of seabed $5009 \mathrm{~m}$ which were cut to a depth of $136 \mathrm{~km}$.

\subsection{Seismicity Cross Section Plane B-B'}

Seismicity cross section plane B-B' (Figure 3.2) was the earthquake hypocenter spread in the region of Pacific Ocean with cross section in the point $5.25^{\circ} \mathrm{N}-1.52^{\circ} \mathrm{S}$ dan $136.15^{\circ} \mathrm{E}-140.77^{\circ} \mathrm{E}$ with a distance of $910 \mathrm{~km}$ as well as the depth of seabed $5008 \mathrm{~m}$ which were cut to a depth of $97 \mathrm{~km}$.

\subsection{Seismicity Cross Section Plane C-C'}

Seismicity cross section plane C-C' (Figure 3.3) was the spread of earthquake hypocenter in the region of Papua with cross section on the point of $1,38^{\circ} \mathrm{N}-4,97^{\circ} \mathrm{S}$ dan $137,09^{\circ} \mathrm{E}-140,91^{\circ} \mathrm{E}$ which was cut to a depth of $171 \mathrm{~km}$. 


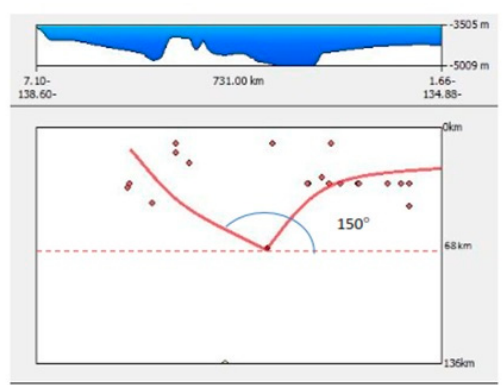

(a)

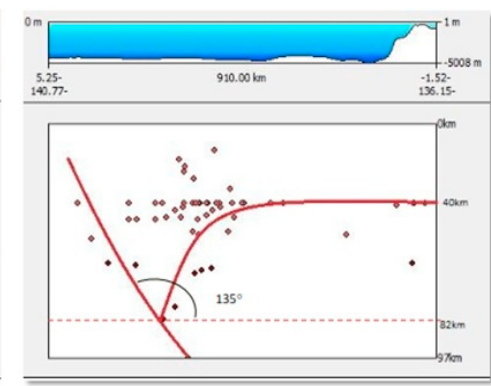

(b)

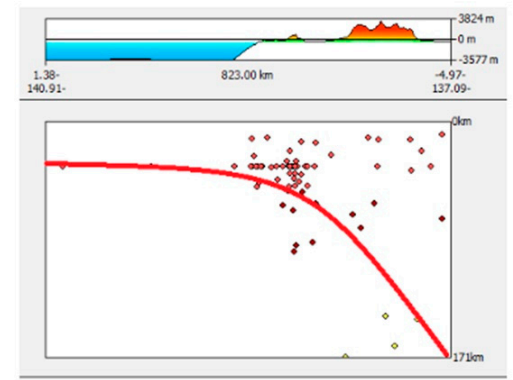

(c)

Figure 2. Seismicity Cross Section Plane (a) A-A'; (b) B-B'; (c) C-C'

\section{Discussion}

Based on the observation on Figure 2 (a) could be seen that the type of earthquake which occurred in Pacific Ocean was shallow earthquakes with the depth of between 0-43 km. Besides, it could be seen that on plate A- $\mathrm{A}^{\prime}$ there was the confluence of two plates which had dip angle $150^{\circ}$ against horizontal in the depth of $\pm 68 \mathrm{~km}$. In this plate, could be seen that most of the earthquake which occurred was earthquake with shallow to medium depth and distributed up to passing under fault. Besides, as could be seen on seismicity cross section plane $A-A^{\prime}$, the seismicity cross section plane B-B' also had subduction confluence point of two plates.

Figure 2 (b) shown plate B-B' had the higher seismicity level compared to plate A-A'. It was indicated by the amount of the hypocenter spread in the region. Besides, the high level of seismicity on plate B-B' was also influenced by the confluence of two plates, they were Pacific plate subducted to Indo - Australian plate with dip angle $135^{\circ}$ against horizontal in the depth of $\pm 82 \mathrm{~km}$.

Based on Figure 2 (c), it is known that the red hypocenter dots were an earthquake which occurred because of fault and local fault or an earthquake which occurred on the surface (shallow earthquake) where those earthquake classification couldn't explain the boundary between the two plates. The yellow hypocenter dots were medium earthquakes which could explain dip angle which occurred in Papua and its surrounding. In the region of Papua and its surrounding, shallow earthquakes occurred under the base surface of Cendrawasih bay. The more eastward the occurred earthquake, it was earthquake which classified into medium earthquake. Therefore, for the region of Papua, the confluence of two plates was located in the point of $-1.77^{\circ} \mathrm{S}$ to $4,97^{\circ} \mathrm{S}$ subducted up to a depth of $180 \mathrm{~km}$ on $1.38^{\circ} \mathrm{N}-4.97^{\circ} \mathrm{S}$. Estimazion which was the confluence of two plates boundary begin from $1.38^{\circ} \mathrm{N}$ subducted to $-4.97^{\circ} \mathrm{S}$. This could also be explained through the form of subduction zone which was shown on Figure 3.3.

\subsection{Subduction Zone Characteritics}

Based on the cross section result of each plane, it was known that the angle which was formed on the hollow dip, which was on the depth of $0-17 \mathrm{~km}$ with dip angle reached to $45^{\circ}$. For the intermediate dip region, there was on the depth of 0-82 $\mathrm{km}$ with the amount of dip angle $135^{\circ}-150^{\circ}$. The analysis showed that the Pacific plate subduction was predicted under the northern mainland. This was supported through the view of the hypocenter spread plot result I the region of the north part of Papua as shown on Figure 3 (a).

Figure 3.4 also explained that the type of earthquake in Papua was the shallow to medium earthquakes. This shallow earthquake usually was caused by active faults which were in Papua, while this medium earthquake was occurred as the cause of the plate activity which moved on the bottom.

Based on the hypocenter spread plot result in Papua, it was known that earthquake with the deepest hypocenter occurred on the depth of $\pm 150 \mathrm{~km}$, with epicentrum which was located on the region of Papua mainland. The hypocenter on that depth was included in medium earthquake 
category $(60-300 \mathrm{~km})$. It indicated that subduction Pacific plate in Papua was not too deep. The hypocenter spread also indicated that shallow earthquake $(0-60 \mathrm{~km})$ was occurred more often compared to medium or deep earthquake

The seismicity cross sectional view on the result of the research showed interaction of two complex plates. It can be seen on Figure 3.1 and Figure 3.2 which was a different area in one territorial waters which was Pacific ocean, but it had two confluences between the plates. This Pacific plate subduction was observed until the northern Papua mainland as seen on Figure 3.3. Those plates interaction showed that the structure of Papua tectonic was complex. It was based on what had previously explained that Papua was an area with complex tectonic which was the confluence of some dynamic plates.

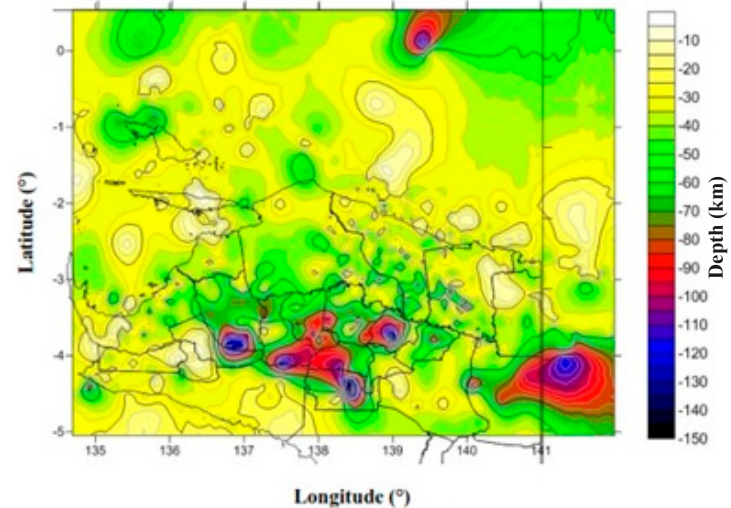

(a)

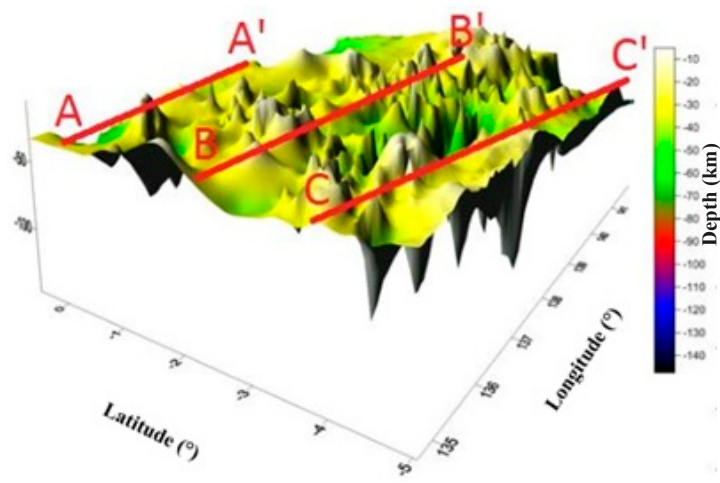

(b)

Figure 3. (a) The Contour of Hypocenter Spread; (b) The Three-Dimensional View of Subduction Zone Using Surfer12

The complex tectonic structure can also be seen through the cross-sectional three-dimensional view of the island of Papua as seen on Figure 3 (b). Based on Figure 3 (b), it could also be seen that from $138^{\circ} \mathrm{E}$ under Papua, there was no earthquake activity which related to subduction system. The earthquake activity in this region was more controlled by active faults activity in the area of Papua. It was shown by earthquake hypocenter which was not too deep. $(\leq 300 \mathrm{~km})$.

\subsection{The Study of Seismotectonic}

Every earthquake would occur again in the same area. The repetition of the earthquake was influenced by seismotectonic condition. This is because the seismotectonic condition really influenced the earthquake activity and greatly effected to the perceived earthquake intensity. The earthquake activity could be known by the study of its focus mechanism. The study of focus mechanism solution of earthquake in this research was done by analysis of Papua historical seismicity since 1976 - 2013 which had magnitude $\geq 6$ Richter scale. From the result of the study, it got some types earthquake focus mechanism in the Northern Papua. The map of the northern Papua focus mechanism solution could be seen on Figure 4 . 


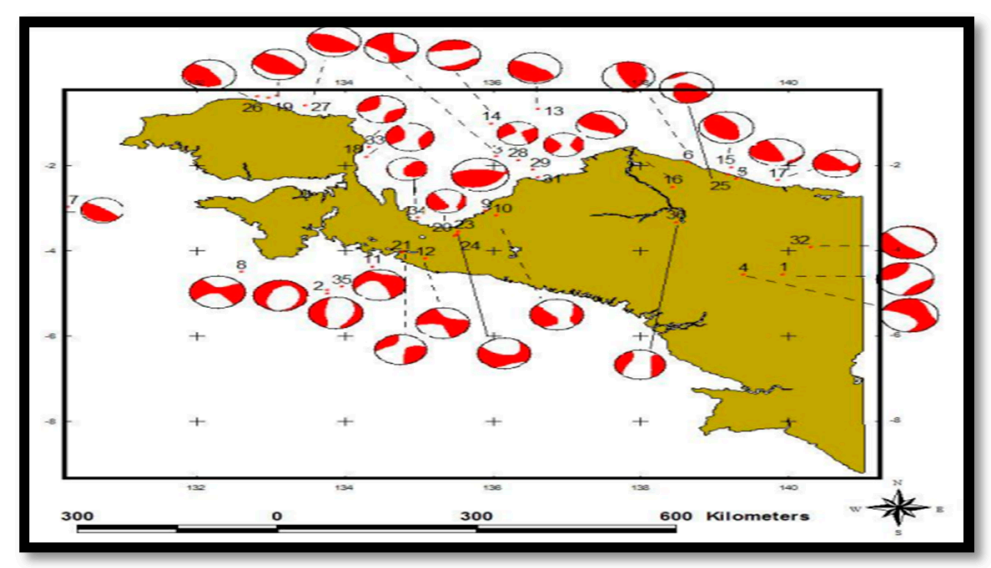

Figure 4. The spread of focus mechanism solution on the earthquake event in the region of the northern Papua since 1976-2013 with magnitude of $>6$ Richter scale

Based on the spread of focus mechanism solution which was shown on Figure 4, it was known that the type of fault on the region of Bird's Head was oblique reverse (the fault which had mixed movement direction, either up or down and moved horizontally). It was in line with the Dow and Sukamto research [19] which stated that the area of head bird compressed to the south since the era of Oligosen. This compression was the result of oblique convergent interaction between IndoAustralian plate and the plate of Pacific continent - Caroline.

On the area of Bird's Neck and Cendrawasih bay had the type of fault called strike-slip. This is because the relative movement of Pacific ocean - Caroline plate and Indo-Australian plate was manifested by the strike stripe movement which may or not correlated with transform fault. This strike-slip movement was seen on the zone system of Sorong - Yapen-Bewani fault from east to west along New Guinea. The fault moved to the left and some researchers stated that this fault formed a displacement along $600 \mathrm{~km} \mathrm{[20].}$

On the earthquake in Bird's Body, the type of fault was oblique reverse. As what had been known in the seismicity cross sectional plate C-C', which also covered bird's body, the region was subduction zone of Pacific plate. However, because of the not-too-deep of the pacific plate subduction, the earthquake activity in this region was more controlled by active faults activity.

\section{Conclusions}

Subduction characteristic in the north of Papua, which is Australian continental plate subducted to the north, followed by the collision and pacific plate subduction to the south on New Guinea trough. Through the study of Papua focus mechanism solution, it is known that the Papua seismotectonic condition is generally affected by oblique reverse fault on the area of Bird's head and Bird's body, strike-slip fault on the area of Bird's Neck and Cendrawasih bay. This shows that earthquake activity in Papua is more controlled by active faults activity which is one of indication that the condition of plate subduction the mainland of Papua is not too deep. Therefore, in this research, it is known that there is conformity between the subduction zone characteristic with Papua seismotectonic condition.

Acknowledgments: We are very grateful to Head of Indonesian Agency for Meteorology, Climatology and Geophysics.

Author Contributions: Miftachul Janah and Yuni Trisnowati analysized the earthquake history data and made model. Supriyadi and Ian Yulianti designed the research. Miftachul Janah, Supriyadi, Ian Yulianti, Yuni Trisnowati, Andya S. P. Putro wrote the paper.

\section{References}

1. DcMets, C.; Gordon, R. G.; Argus, D. F.; Stein, S. Current plate motions. Geophysical journal international. 1990, 101, 425-478. 
2. Puntodewo, S. S. O.; McCaffrey, R.; Calais, E.; Bock, Y.; Rais, J.; Subarya, C.; Wdowinski, S. GPS measurements of crustal deformation within the Pacific-Australia plate boundary zone in Irian Jaya, Indonesia. Tectonophysics. 1994, 237, 141-153.

3. Bock, Y.; Prawirodirdjo, L.; Melbourne, T. I. Detection of arbitrarily large dynamic ground motions with a dense high-rate GPS network. Geophysical Research Letters. 2004, 31, 1-4.

4. Pubellier, M.; Ego, F. Anatomy of an escape tectonic zone: Western Irian Jaya (Indonesia). Tectonics. 2002, 21,1-4.

5. Bird, P. An updated digital model of plate boundaries. Geochem. Geophys. Geosyst. 2003, 4, 1027-1080.

6. Pubellier, M.; Ego, F. Anatomy of an escape tectonic zone: Western Irian Jaya (Indonesia). Tectonics. 2002, 21,1-17.

7. Abers, G. A.; McCaffrey, R. Active Deformation in the New Guinea fold-and-thrust belt: Seismological evidence for strike-slip faulting and basement-involved thrusting. J. Geophys.Res. 1988, 13, 332-354.

8. Sapiie, B., \& Cloos, M. Strike-slip faulting in the core of the Central Range of west New Guinea: Ertsberg Mining District, Indonesia. Geological Society of America Bulletin. 2004, 116, 277-293.

9. Bailly, V.; Pubellier, M.; Ringenbach, J. C.; De Sigoyer, J.; Sapin, F. Deformation zone 'jumps' in a young convergent setting; the Lengguru fold-and-thrust belt, New Guinea Island. Lithos. 2009, 113, 306-317.

10. Lay, T.; Kanamori, H. Earthquake doublets in the Solomon Islands. Phys. Earth Planet. Inter. 1980, 21, 283304.

11. Schwartz, S. Y.; Lay, T.; Ruff, L. J. Source process of the great 1971 Solomon Islands doublet. Phys. Earth Planet. Inter. 1989, 56, 294-310.

12. Park, S. C.; Mori, J. Triggering of earthquakes during the 2000 Papua New Guinea earthquake sequence. Journal of Geophysical Research: Solid Earth. 2007, 112, 1-14.

13. Poiata, N.; Koketsu, K.; Miyake, H. Source processes of the 2009 Irian Jaya, Indonesia, earthquake doublet. Earth, planets and space. 2010, 62, 475-481.

14. Lay, T.; Kanamori, H. Earthquake doublets in the Solomon Islands. Physics of the Earth and Planetary Interiors. 1980, 21, 283-304.

15. Boore, D. M. Simulation of ground motion using the stochastic method. Pure Application Geophysics . 2003, 160, 635-676.

16. Brown, J. R.; Beroza, G. C.; Ide, S.; Ohta, K.; Shelly, D. R.; Schwartz, S. Y.; Wolfgang, R.; Martin, T.; Kao, H. Deep low-frequency earthquakes in tremor localize to the plate interface in multiple subduction zones. Geophysical Research Letters. 2009, 36, 1-5.

17. KanHayes, G. P.; Wald, D. J.; Johnson, R. L. Slab1. 0: A three-dimensional model of global subduction zone geometries. Journal of Geophysical Research: Solid Earth. 2012, 117, 1-15.

18. Kanamori, H. Rupture process of subduction-zone earthquakes. Annual Review of Earth and Planetary Sciences. 1986, 14, 293-322.

19. Dow, D.B.; Sukamto, R. Western Irian Jaya: the end-product of oblique plate convergence in the Late Tertiary. Tectonophysics. 1985, 106, 109-139.

20. Waschsmuth, W., and F. Kunst. "Wrench fault tectonics in northern Irian Jaya." (1986): 371-376. 